\title{
BLUEPRINTING FORESTRY EDUCATION PATTERNS IN CANADA
}

\author{
By K. G. FENSOM ${ }^{1}$
}

\begin{abstract}
Neither forestry education, nor any other type of higher education in Canada, can be completely evaluated outside the context of the different elementary and secondary school systems from which university undergraduates are recruited, the character of the immediate university environment and, in the final analysis, the proven ability of qualified graduates to be imaginative and flexible in their thinking and able to cope effectively with a rapidly expanding mass of knowledge and technology.

One of the major difficulties in making conventional appraisals is that there are so many theories about education. This applies to all forms of education from kindergarten through university at the undergraduate level to post-graduate study and research. It is hardly an exaggeration to state that for every idea there is a counter idea. The commencement of disciplined schooling at the age of five years-and sometimes at three-has been as passionately advocated as it has been denigrated. Some say that the accelerating output of scientists and engineers in Russia poses a threat to world security while others profess to believe that Soviet higher education is a failure measured against the Western emphasis on the development of creative intellect critical of society and its values. The six hour secondary school day has been vehemently discussed for and against: as have examinations; homework; the place of machine programming in secondary education; the 200-day school year; the relative importance of junior and senior secondary schools and junior colleges; the amount of time and emphasis that should be devoted to art, music, industrial arts, home economics and other high school electives; upgraded elementary school classes designed to spur youngsters to hustle through each subject at their own pace; the teaching of French in the lower elementary school grades not only in Quebec but in all provinces; high school extension campuses in foreign countries; recognition that the maximum use of eyesight is a product of growth that should be nurtured in the early formative years; flexible scheduling; team teaching; and numerous other items.

It is encouraging and stimulating that there are so many new and novel ideas about how to achieve better educational standards. The catch is that no matter how well reasoned is an opinion it is only an opinion until it is tested laboriously by trial and error over a period of years-and under controlled and carefully observed conditions-to discover whether or not it is valid. This kind of testing is so costly and cumbersome that, with few exceptions, it is impractical. Some schools, colleges and universities
\end{abstract}

\footnotetext{
${ }^{1}$ Forestry and Wood Products Consultant, P.O. Box 5072 Postal Station 1., Vancouver 13, B.C.
} 
are so different from the normal patterns as to be unique, but all together these establishments constitute a small drop in the educational bucket, and in any case-and no matter how successful are their programs-they do not necessarily point the way towards wholesale revisions of existing educational practices. What can be done successfully at one institution in a certain locality with certain personnel may or may not be the best potential nationwide standard.

The urgent requirement in the educational field - and one, fortunately, that is fully recognized-is that there be more intensive and systematic research of cause and effect. Since such research is based on scientific analysis of a vast amount of processed data the resulting criteria, when interpreted in terms of judgment, are more reliable than ideas that necessarily stem from limited personal experience. Many investigations have been undertaken in Canada-Royal Commission reports in the different provinces; committee reports; special studies compiled by school boards, Departments of Education, education associations, universities, professional bodies and individuals; and others.

These surveys have not only been informative but have frequently pointed the way towards innovation and reform. It was recently reported, for instance, that unless government, business and the universities raise millions more for research in the next five years Canada's graduate schools will be filled with third-rate students being taught by third-rate teachers. This sobering statement is not someone's abstract idea, but a deduction resulting from a special investigation jointly supported by the Canada Council and the Humanities and Social Science Research Council of Canada. Problems were pin-pointed in this report and recommendations were made which have not as yet been implemented-but concerning which action may be taken in the near future.

Many of the recommendations made in the 1960 Report of the Royal Commission on Education, Province of British Columbia, have been adopted in the secondary school system of that province.

Dr. John B. Macdonald, President of the University of British Columbia, described potential needs in his 1962 publication, "Higher Education in British Columbia and a Plan for the Future". He stated that 37,000 students would be seeking post-high school education in 1970 in British Columbia, an increase of about 20,000 over the number in 1962; and he stressed that enrolment of this increased number at existing institutions would critically distort their structures-especially those at the University of British Columbia. $\mathrm{He}$ therefore recommended decentralization and the immediate establishment of a four-year degree-granting college in the western Lower Fraser Valley as well as a number of two-year regional colleges to be located in designated parts of the province. These and other recommendations have already been favourably considered by the provincial government with the result that legislation has been passed, and land acquired for, the proposed new Simon Fraser University to be located in the municipality of Burnaby near Vancouver.

Canadian universities are presently planning a royal Commission-style study of university financing. It is hoped that ways and means will be indicated of 
obtaining sufficient funds in a constitutional manner to meet their growing needs. Sponsored by the Canadian Universities Foundation headed by Dr. Claude Bissell, President of the University of Toronto, and supported with a matching grant up to a maximum of $\$ 100,000$ from the Ford Foundation, it is expected that this study will specifically define a recommended pattern of financing up to 1975 .

All these and other studies are the necessary prelude to action, since without this new knowledge and information plans based on projections into the future cannot be formulated with the same degree of confidence. Education in Canada both at pre-university and university levels has been well served by these various specialized studies, and it can be predicted that many more useful complementary investigations will be undertaken.

An entirely different situation prevails in the field of forestry in Canada. Forestry educators, as much as those in other professions, should be provided with every possible tool in appraising their curricula, student body, teaching staff, facilities and job opportunities for graduates. One of those tools-but one they do not have-is an integrated accumulation of scientific research tabulations, graphs, reviews of questionnaires, interview summaries and statistical analyses compiled on a provincial and nation-wide basis. Dr. Clark Kerr, President of the University of California, speaking recently at Harvard, said-"The university is being called upon to educate previously unimagined numbers of students, to respond to the expanding claims of national service, to merge its activities with industry as never before, to adjust to new intellectual currents".

Each Faculty of Forestry within each university of which it is a part has the monumental task of constantly adjusting to changing conditions and demands. What is today was not yesterday and will not be tomorrow. Projections into the future based on correlated and co-ordinated data are, therefore, a must in planning. The challenge is there and the spirit and desire are there as far as the educators are concerned, but how can these projections be made when these data are not available? Canadian forestry educators have done a remarkable and praiseworthy job. Literally they have created the profession of forestry in this country. But in these times of space probes, moon shoots and orbital flights it is becoming increasingly difficult to chart the future course of forestry education.

Forestry like everything else is in a state of flux. This is not necessarily bad. In fact it could be very good, but it has been said that its professionals seem to be less sure of either their professional identity or of the rightness of their long term objectives than are engineers, doctors and members of professions with well established and accurate public images. When foresters themselves question the validity of forestry as a profession, as some of them do; when the stature of the profession is down-graded by foresters in terms of its social impact, as sometimes it is-it is not to be wondered at that the public is confused, and that this confusion is reflected in misconceptions that undermine the support and understanding that foresters must have if they are to successfully practise their profession. Could it be that the forester himself rather than the character of the profession itself is to blame? Could it be that he is not the kind of individual generally capable of adding the 
social graces to his technical abilities in that "second mile" referred to by Dr. W. E. Wickenden, then President of the Case Institute of Technology, when he addressed the Engineering Institute of Canada in 1948? Said Dr. Wickenden-"Every calling has its mile of compulsion, its daily round of tasks and duties, its standard of honest craftsmanship, its code of man-to-man relations, which one must cover if he is to survive. Beyond that lies the mile of voluntary effort, where men strive for excellence, give unrequited service to the common good, and seek to invest their work with a wide and enduring significance. It is only in this second mile that a calling may attain the dignity and distinction of a profession."

There are very few foresters in Canada who have not successfully negotiated Dr. Wickenden's first mile, but how many or how few have been equally successful with the second mile? And if they have failed in this second category, which Dr. Wickenden defines as the "essence of professionalism", why have they failed? Is it because they were wrongly motivated, or badly counselled, or not counselled at all, or lacking the proper combination of educational elements throughout their elementary and high school training?

Or is it because university standards have been too low, or undergraduate courses too short, or the desired kind of graduate study not available? Has there been too little or too much specialization, too little or too much subject matter, too much or too little restriction on electives, too little or too much flexibility in curriculum arrangement as between the so-called "core requirements" and other subjects? Is it because the social sciences and the humanities have been neglected or partially neglected, or because there has been insufficient integration of forestry and the biological and physical sciences? Is it because courses have remained too static, or because they have been juggled so frequently as to destroy continuity? Has there or has there not been a lack of balance between traditional education patterns, a lack of facilities for the training of forest technicians, and a lack of coordinated planning between forest schools in the areas of exchanging undergraduates and the elimination wherever possible of duplicated specializations?

Statements of opinion can be offered in respect to these and countless other relevant queries. In fact an educator would not be a good educator unless he had firm opinions based on his own experience, reading and background of knowledge. He has to make up his mind no matter how many-sided is the issue because he must make decisions. He has done and continues to do a good job with the information at hand. This good job has been very good indeed, and Canada is fortunate in having had high-calibre and dedicated forest educators. No educator, however, can be satisfied that he has found the right answers unless he has had available as references and checks scientifically compiled data that are indicative of trends, deviations and performance. A noticeable and serious gap in the forestry education picture in Canada is the almost complete absence of such data.

Analyses of the secondary school systems and the qualifications and aptitudes of the human product in each of the provinces as related to potential university forestry education never have been conducted; nor have analyses been made of managers' and executives' relations with foresters in 
their employ, of the reasons why foresters become dissatisfied with and unhappy in their occupations, of the special experiences of individual foresters that are indicative and significant, of potential employment trends in relation to present and future technology. Surveys involving the use of statistical techniques-stratified random sampling, establishment of confidence limits of a proportion, variance and value of a proportion, rank order established by scalogram methods, electronic computer programming, etc.-have not as yet become essential prerequisites in the development of educational forestry blueprints across Canada. But they are essential and, as much if not more than any other data, these findings are needed as directional signposts.

Up to the present the only specialized surveys of forestry education in North America have been made in the United States. In 1930-32 Henry S Graves, Dean of the School of Forestry, Yale University, and Cedric $\mathbf{H}$. Guise, Assistant Professor of Forest Management, Cornell University, conducted a Forest Education Enquiry which terminated in the publication of the book entitled "Forest Education" which is still a standard reference. Then in 1960 two additional national surveys were commenced, one under the auspices of the Society of American Foresters and financed jointly by the S.A.F. and the Old Dominion Foundation in the amount of approximately $\$ 54,500$, and the other sponsored by the Society of Wood Science and Technology and supported by National Science Foundation funds in the amount of about $\$ 29,900$. The S.A.F. survey was undertaken by Drs. Samuel T. Dana and Evert Johnson and the other by Dr. Everett Ellis. And so the United States is three surveys ahead of Canada in this all-important area of forestry education.

Our friends below the border would not have taken this lead in national forestry education appraisal had action been taken as recommended in the 1947 report of the Education Committee of the then Canadian Society of Forest Engineers. That report was presented at the 1947 annual meeting of the C.S.F.E. in Vancouver, was approved unanimously, and a Ways and Means Committee was appointed for the purpose of searching for financial support for the suggested survey. Unfortunately the necessary funds were not found, and no action was taken. However, at the 1962 annual meeting of the Canadian Institute of Forestry - by coincidence also held in Vancouver-a motion was passed which reaffirmed the interest of the professional society in this proposed project.

What is required is a completely unbiased scientific study-unbiased in the sense that the compiled factual data should be permitted to tell their story without being prejudiced by any preconceived ideas as to the answers, and scientific in the sense that the study should be set up as a research project with proper experimental design, techniques and procedures. It is assumed that all the forestry schools would co-operate to the fullest extent possible, that their staffs and students would be available for consultation, and their records for examination. It is also assumed that it would be recognized that the study would be without value unless it were broadly based, constructively critical and not restricted as to the findings which subquently would or would not be implemented by forestry educators in accordance with their individual judgement. 
This kind of study would require financing in the range from $\$ 25,000$ to $\$ 35,000$. It would take from one and a half to two years to complete, and it would require a staff of one director plus stenographic and statistical assistants. It is one of the most important potential projects in the whole field of forestry in Canada, and its successful sponsoring by the Canadian Institute of Forestry would constitute a major contribution of inestimable value.

\section{REFERENCES}

"The Training of a Forester", Gifford Pinchot. J. B. Lippincott Company. 1914.

"Forest Education", Henry S. Graves and Cedric H. Guise, Society of American Foresters, 1932. "The Professional Engineer", Esther Brown. Russell Sage Foundation. 1936.

"Surveys of American Higher Education", Walter Eells. Carnegie Foundation. 1937.

"Report of the Royal Commission on Dominion-Provincial Relations". Ottawa, 1940.

"Les Humanités Classiques dans la Société Contemporaine", M. Lebel. Université de Laval. 1944.

"Report of the Royal Commission on Education in Ontario", Province of Ontario. 1950.

"Forestry and Its Career Opportunities", Hardy L. Shirley. McGraw-Hill Book Co. Inc. 1952.

"General Education in School and College", Harvard Press. 1952.

"Curriculum Trends in Canadian Education", Harold L. Campbell. Gage, Toronto. 1953.

"So Little For the Mind", Hilda Neatby. Clarke Irwin \& Co. Ltd. 1953.

"The Teaching of French and English in the French Schools of Quebec", M. Lebel. Culture XVI. 1955.

"Career Preferences of Medical Students in the United States". University of Chicago. 1956.

"La Recherche Forestière a ['Université Laval", L. Z. Rousseau et A. Lafond. Culture XVII. 1956.

"The Development of Education in Canada", Charles E. Phillips. Gage, Toronto. 1957.

"Soviet Education", George L. Kline. Columbia University Press. 1957.

"Technical Education and Social Change", Stephen F. Cotgrove, PhD. George Allen \& Unwin Ltd. 1958.

"Etudes sur le Canada Français", P. Garique. Université de Montréal. 1958.

"Report of the Manitoba Royal Commission on Education", Province of Manitoba. 1959.

"Report of the Royal Commission on Education", Province of Alberta. 1959.

"Report of the Royal Commission on Education", Province of British Columbia. 1960.

"Characteristics of Engineers and Scientists", Lee E. Danielson. University of Michigan. 1960.

"The Organization of Education at the Secondary School Level". Canada Bureau of Statistics, Ottawa. 1961.

"Slums and Suburbs", James B. Conant. McGraw-Hill Book Co. Inc. 1961.

"The Schools", Martin Mayer. Harper. 1961.

"Tomorrow's Illiterates", Charles C. Walcutt. Atlantic-Little Brown. 1961.

"Education and the Common Good", Philip E. Phenix. Harper. 1961.

"Guide to Better Schools", J. Lloyd Trump and Dorsey Baynhan. Rand McNally. 1961.

"Higher Education in British Columbia and a Plan for the Future", John B. Macdonald. University of British Columbia. 1962.

"Research in the Humanities and Social Sciences in Canada", Bernard Ostry. Humanities and Social Science Research Council of Canada. 1963.

"Forestry Education in America-Today and Tomorrow", S. T. Dana and F. W. Johnson, Society of American Foresters. 1963. 